\title{
AINDA É POSSÍVEL FALAR DE ESCOLA "À FRANCESA"? ALGUMAS REFLEXÕES SOBRE AS POLÍTICAS EDUCACIONAIS NO CONTEXTO CONTEMPORÂNEO*
}

\author{
ANDRÉ ROBERT
}

\begin{abstract}
RESUMO: Este artigo estuda como uma organização específica do sistema escolar como a francesa, tomada como exemplo (que deveria ser válido para muitos outros sistemas do mesmo tipo), reage no contexto contemporâneo de pós-modernismo e globalização. A questão central é: está ocorrendo uma dissolução inevitável dos padrōes específicos em razão da crise presumida ou existe alguma possibilidade de renascimento sobre uma nova base? Quatro etapas dão ritmo ao texto: a noção de política educacional; a crise da instituição escolar; as "soluçôes" temporárias; algumas pistas para o futuro.
\end{abstract}

Palavras-chave: Instituição escolar. Exceção nacional. Crise. Políticas educacionais. Pós-modernismo.

Is IT STILL POSSIBLE TO SPEAK ABOUT SCHOOL "THE FRENCH WAY"? A FEW REFLECTIONS ON EDUCATIONAL POLICIES IN THE CONTEMPORARY CONTEXT

ABSTRACT: This paper explores how a specific organization of the school system, like the French one, taken as an example (supposed to be valid for many other such kinds of systems), reacts in the contemporary context of postmodernism and globalization. The main question is: is there an unavoidable dissolution of the specific patterns due to the alleged crisis of school or is a renaissance on a new basis possible? Four steps give its rhythm to the

\footnotetext{
* Tradução de Alain François, com revisão técnica de Ivany Pino.

** Professor da Universidade Lyon 2 (França). E-mail: adrobert@inrp.fr
} 
Ainda é possível falar de escola “à francesa”? Algumas reflexões sobre as políticas...

text: the notion of educational policy; the crisis of school institution; the temporary "solutions"; some tracks for the future.

Key words: School institution. National exception. Crisis. Educational policies. Postmodernism.

त4

m 1996, o historiador Claude Lelièvre intitulava uma obra L'école "à la française" en danger? (A escola "à francesa" em perigo?), supondo assim a existência de um modelo escolar francês específico e de graves ameaças próprias a questioná-lo. Pretendemos retomar esse questionamento aqui, não para analisar mais uma vez os componentes desse modelo e estudar em detalhe as evoluções políticas internas que podem fazê-lo mudar de rumo, mas, mais geralmente - tomando a França como horizonte de referência -, para interrogar as tendências que conduzem a sustentar a tese de uma "crise" da instituição escolar em países comparáveis e as relações que um modelo nacional pode manter com as correntes de idéias, os contramodelos, as pressões ou injunções oriundas de esferas internacionais mais ou menos bem identificadas, no âmbito da globalização. ${ }^{1}$ Portanto, em forma de esboço, vamos tentar submeter à prova reflexiva não apenas o que foi chamado de "a exceção francesa", mas, mais amplamente, o que generalizaremos sob o nome de "exceção nacional" (tendo em vista, no mundo inteiro, organizações de sistemas de ensino que, embora concretamente diferenciadas, estão bastante próximas, pois se reúnem em torno de características como: a idéia de serviço público, o papel preponderante do Estado central - ainda que afrouxado por medidas de descentralização -, o acesso do maior número possível de alunos aos níveis escolares mais elevados [massificação, democratização] e o caráter não-dogmático dos conteúdos ministrados). Em outras palavras, nossa pergunta será: em que medida "exceçôes nacionais" dessa ordem podem resistir tanto à crise que parece ter-se instalado na escola, em razão das contradições inerentes à massificação-democratização, da incerteza das finalidades atribuídas à escola obrigatória e da ruptura de certos equilíbrios, como a certos aspectos de um pensamento educacional mundial uniforme, dominado por valores econômicos? A resposta a esse questionamento passará por quatro etapas: definição da noção de política educacional; delimitação dos elementos da crise da escola contemporânea; análise de alguns aspectos das "soluções" realmente 
encontradas, embora talvez muito temporariamente (equilíbrios precários); e apresentação de algumas pistas para o futuro. Fundamentamonos na hipótese segundo a qual a escola "à francesa” pode servir de ponto de apoio, ao possibilitar uma certa forma de generalização que seja eloqüente para os leitores de outras culturas nacionais.

\section{A noção de política educacional no contexto contemporâneo}

Num regime democrático, e mais particularmente no âmbito de um Estado centralizado, deve-se entender política pública de educação primeiro como a ação sobre as instituiçôes escolares - desenvolvida em nome de uma maioria parlamentar - exercida por um governo e seu ministro da Educação nacional. Embora essa ação possa eventualmente se concretizar em leis, quando os projetos têm uma certa amplidão (fala-se então de "reformas"), ela costuma se traduzir antes por um conjunto de decretos, portarias e circulares que a administração está encarregada de fazer executar, os quais colocam como que por necessidade a educação num fluxo permanente de mudanças. Entre essas decisões, algumas são técnicas, outras, mais deliberadamente políticas no sentido em que referem a uma orientação embasada num programa e em princípios de natureza filosófica, em última análise. Entretanto, cabe observar que, nos regimes ditos de alternância, ainda que existam mesmo diferenças de orientação filosófica entre governos de direita e de esquerda, a necessidade reconhecida de uma "continuidade do Estado" leva a mitigar parte das modificaçōes de grande envergadura, e que as diferenças se façam sentir na margem. Contudo, embora indispensável, essa leitura empírica, superficial, deve ser complexificada, pois ela apenas diz respeito aos aspectos voluntários e conscientes da ação de um único tipo de ator, o ator governamental (o qual, por sinal, também é freqüentemente atravessado por lutas de poder internas, motivadas por interesses táticos e/ou por clivagens de idéias dentro da mesma corrente [mouvance]).

Sob essas aparências da vontade consciente, uma leitura "sintomal" ${ }^{\prime 2}$ vai de fato esforçar-se por detectar os efeitos de determinantes estruturais ou infra-estruturais, como os da economia ou, mais precisamente, os das relaçôes de classes relativamente à questão da posse do capital econômico. Independentemente de o poder ser exercido pela direita ou pela esquerda, é incontestável que uma sociedade de economia capitalis- 
Ainda é possível falar de escola “à francesa”? Algumas reflexões sobre as políticas...

ta apenas pode abrigar uma escola ela mesma capitalista. Assim, em 1971, os sociólogos A. Baudelot e R. Establet intitularam uma obra: L'école capitaliste en France (A escola capitalista na França). Ainda que não se possa esquecer disso, a capacidade heurística de tal afirmação, fortemente mecanicista, não está ganha de antemão quando se trata de chegar a uma compreensão fina do funcionamento interno das instituições escolares, cujas carreiras (filières) são cada vez mais diferenciadas numa organização mais e mais complexa. ${ }^{3}$ Resta que, assim como qualquer outra, uma política escolar não está num estado de "ausência de gravidade" econômica em relação ao meio nacional e internacional. Isso é comprovado tanto pela missão principal atribuída, hoje em dia, a segmentos cada vez mais numerosos do sistema educativo, preparar diretamente ao ingresso no mercado do trabalho, como pela potencialização do tema do "life long learning", articulado em grande parte na flexibilidade dos empregos, particularmente valorizado em nível europeu. Entre os outros determinantes não-conscientes de uma política escolar, citaremos ainda os demográficos.

Se voltarmos, então, à idéia de autonomia relativa da esfera escolar em relação a esses determinantes, somos levados a introduzir na noção de política escolar a ação dos atores sociais, cujos responsáveis no poder não podem ignorar seja por antecipação e cautela, seja por coerção, sob a pressão de protestos, greves e outros movimentos sociais. Assim, uma política escolar define uma cena ou uma arena na qual interesses antagonistas entram em confrontação e podem vergar a vontade do poder. Grupos mais ou menos estruturados, partidos, sindicatos, "coordenações", ${ }^{4}$ movimentos pedagógicos etc. que também desenvolvem uma política, a qual pode ir do simples protesto reativo à defesa de projetos reformadores muito coerentes, participam da mesma forma da construção da realidade de uma política escolar característica de um dado período.

Além da intervenção de grupos estruturados e de situações dramáticas que resolvem problemas pela crise pontual, o que tenderia a justificar uma visão bastante pejorativa do processo da decisão nos Estados centralizados (Archer, 1979), existem outros modos de intervencionismo da sociedade. Estes, embora mais silenciosos, não deixam de ser muito influentes e, conquanto não se inscrevam em uma noção de vontade coletiva expressa, mas antes em agregados de comportamentos individuais, devem ser integrados à noção de política escolar: trata-se das práticas co- 
tidianas, corriqueiras, obviamente características de um grupo social, mas não concertadas no espaço público, pelas quais seus membros se posicionam relativamente à instituição escolar e contribuem a vergar sensivelmente o curso da política educacional. Assim, desde o começo dos anos de 1980, pode-se discernir um modo de comportamento das famílias mais bem informadas que se aparenta a um verdadeiro "consumismo" em relação aos estabelecimentos escolares (Ballion, 1982); os sociólogos G. Langouët e A. Léger batizaram de "zapping escolar" a prática dos pais que escolhem ora a escola pública, ora a escola particular, mais por cálculo interessado do que por razões ideológicas (Langouët \& Léger, 1997). No período mais recente, o crescimento dos fenômenos de segregação urbana e dos comportamentos consumistas das classes médias e superiores, que privilegiam tal ou tal estabelecimento a despeito das regras vigente, ${ }^{5}$ tem contribuído para criar, dentro do próprio serviço público, disparidades consideráveis que levaram ao recuo da "mescla social" (mixité sociale), ao surgimento de guetos escolares com muitas dificuldades e ao aprofundamento das diferenças entre "centros" favorecidos e "periferias" que acumulam todos os problemas (van Zanten, 2001). Ainda que não sejam constituídos em política consciente, esses comportamentos humanos não deixam de ter incidências incontestáveis sobre as políticas, às quais seus efeitos se incorporam.

Finalmente, outros fatores contemporâneos devem ser levados em conta. Várias instâncias vêm disputar com o Estado sua preeminência política em matéria de organização e de regulação educacional. O conceito de "glocalização" (Robertson, 1992) surgiu para designar alianças singulares entre o "local" e o "global", isto é, entre o infra- e o supraestatal, que acabam deixando de fora o papel do Estado Nacional, o qual prevaleceu por muito tempo e é considerado indispensável nos sistemas centralizados. Por um lado, no âmbito de um processo de descentralização (no exato momento em que outros países de tradição descentralizada, como a Inglaterra, rumavam para mais centralização, especialmente, em matéria de currículo, uma margem de iniciativa maior foi conferida aos escalóes locais (Duru-Bellat \& van Zanten, 1999 e Politiques scolaires et changements institutionnels, p. 24-26). As coletividades locais (municipalidades, conselhos departamentais e regionais) foram cada vez mais elevadas à condição de tomadores de decisōes no campo educativo (van Zanten, apud Cardi \& Chambon, 1997, p. 165-185), e os atores políticos oficiais vêm assim se multi- 
Ainda é possível falar de escola “à francesa”? Algumas reflexões sobre as políticas...

plicando com toda legitimidade. Mesmo se seu papel permanece central, pode-se às vezes indagar-se se não estamos assistindo a uma desimplicação do Estado em favor de outros escalóes de responsabilidade, induzindo uma redefinição da própria noção de política nas sociedades pós-industriais na era da globalização. Como alguns políticos ultraliberais apregoam abertamente a teoria do "menos Estado", existe o risco de este deixar seu lugar a outros reguladores situados abaixo ou acima dele. Por outro lado, de fato, instâncias supra-estatais estão ganhando cada vez mais influência. Embora, em escala da Europa, o Conselho da União Européia (UE) não tenha competência para intervir na política educativa dos países-membros, um ministro não pode ignorar trabalhos, publicações e incentivos do Conseil Éducation e da Commission Éducation et Formation (Nóvoa, 1998). Em nível mundial, estamos assistindo a uma circulação intensificada de idéias e dispositivos educativos (movimento obviamente iniciado há muito tempo), à difusão de certas orientações educativas e à promoção de novos valores na escola, tais como a gestão e o mercado, propalados pelos grandes organismos internacionais, por redes ou por "think tanks" (bancos de idéias) mais ou menos informais (van Zanten, 2004). Os tomadores de decisões educativas nacionais podem tanto menos ficar insensíveis diante disso que comparações internacionais instrumentadas sobre os desempenhos do sistema e dos alunos os convidam freqüentemente a buscar remediações e, portanto, a mudar sua política.

Portanto, ao todo, uma política educativa nacional abarca, num contexto mundial cuja influência crescente não deve ser esquecida, um conjunto de intervenções oriundas dos diversos atores sociais assim como - a seu próprio modo - das estruturas, em particular econômicas. Tudo isso se cristaliza em torno da ação consciente empreendida em matéria de educação pelos representantes temporários (eleitos) e permanentes (administradores) do Estado, ${ }^{6}$ e produz efeitos in fine. Esses efeitos podem quer ser conformes às expectativas, quer se revelar perversos, em defasagem radical com as expectativas, ao menos com as alardeadas nas intenções iniciais e, então, induzir reações críticas.

\section{Elementos da crise da instituição escolar}

Falar de crise a propósito da situação escolar na maioria dos países desenvolvidos é um lugar-comum, e a França não foge à regra. Em- 
bora a hipótese não deva ser recusada apenas sob o pretexto de que se tornou corriqueira, parece necessário delimitar vários níveis de emprego do termo e das realidades que designa. Existem um nível conjuntural ou de superfície, um nível estrutural e um nível ainda mais profundo, que talvez pudesse ser chamado de filosófico, por remeter aos fundamentos últimos, aos princípios sobre os quais um sistema se fundamenta. "Crise" tem a mesma raiz que "crítica": é um momento crítico na vida de uma pessoa, de uma sociedade ou de uma instituição, em que as contradições, as tensões, os conflitos exacerbam-se a ponto de porem em perigo o equilíbrio precedente. Portanto, trata-se antes de algo como a fase aguda de uma doença. Crise e crítica vêm do mesmo verbo grego, krinein: julgar, passar no crivo, examinar, discriminar; assim, a crise chama a análise, a crítica, no sentido de exame aprofundado e detalhado, que podem levar a remédios, a soluçôes. No primeiro nível, conjuntural, podemos discernir, na vida das instituiçôes educativas, momentos de crise mais ou menos aguda, tais como a França conheceu um, muito intenso, na primavera de 2003. Este se traduziu por manifestaçóes e greves que duraram por dois meses e afetaram profundamente a vida dos estabelecimentos escolares. Além das reivindicaçōes precisas expressas pelos docentes (em particular quanto à questão da idade da aposentadoria), esse movimento de contestação tem geralmente sido interpretado como a revelação de um "mal-estar dos docentes" perante as dificuldades crescentes enfrentadas no exercício de seu ofício. E, de fato, há aproximadamente duas décadas, as condições de ensino evoluíram - não apenas na França mas em todos os países onde a massificação afetou o ensino secundário e onde se formaram guetos que acolhem as populações fragilizadas -, obrigando os docentes a sempre terem de recriar pessoalmente as condições de sua autoridade onde, antes, esta costumava lhes ser garantida pela instituição de modo bastante confortável. Os professores primários e secundários dizem-se insuficientemente amparados (inclusive em termos de meios materiais) para conseguir implementar os dispositivos pedagógicos aptos a auxiliarem os alunos que apresentam dificuldades de aprendizado, manifestam cada vez menos apetite pelo saber e, às vezes, são muito violentos. Mesmo assim existem professores que se recusam expressamente a assumir uma função de educação e querem se limitar a um papel de transmissão do saber, excluindo toda consideração sobre as condições conjunturais prévias dessa transmissão. Essa clivagem entre os docentes, 
Ainda é possível falar de escola “à francesa”? Algumas reflexões sobre as políticas...

mais sensível no secundário, também constitui um indicador de crise de caráter mais estrutural.

No segundo nível de análise, pode-se dizer que, já há 20-30 anos, certas formas de contradiçôes internas vêm aprisionando os sistemas educativos engajados na massificação. As finalidades da educação multiplicaram-se tanto que ninguém mais consegue achar seu rumo: pede-se, ao mesmo tempo, que o sistema educativo (e conseqüentemente os docentes) instrua, eduque, socialize, "coloque o aluno no centro" (sentido da lei de orientação de 1989 que ainda rege o sistema francês), dê chances iguais a todos, faça com que todos tenham êxito e selecione as elites, eleve o nível geral e responda aos desafios econômicos, dê uma cultura geral e prepare para o emprego, profissionalize, promova a cidadania, lute contra a exclusão social, reduza a violência, compense certas falhas dos pais e, globalmente, traga remédios aos males sociais que outras instituições não conseguem curar... Conseqüentemente, os grandes princípios, que certos sociólogos (por exemplo, J.C. Derouet, que se inspira em L. Boltanski e L. Thévenot) (Derouet, 1992) chamam de "regimes de justiça", aparecem dispersados, carentes de unidade, ao passo que, na antiga percepção da escola, um deles emergia nitidamente (o princípio "cívico") e definia exatamente as missões, criando assim segurança nos docentes. Uma outra manifestação do fenômeno de crise estrutural é o estatuto do colégio único ou colégio para todos, que acolhe a totalidade de uma faixa etária $\left(5^{\mathrm{a}}\right.$ a $8^{\mathrm{a}}$ séries, 11-15 anos). ${ }^{7}$ Para certos analistas, o colégio, no que diz respeito a seus conteúdos e métodos, inscreve-se numa concepção elitista e não soube reformar-se para se adequar a sua nova finalidade, que deveria ser a de dispensar uma "cultura comum", uma base mínima comum a todos; para outros, uma tal reforma seria uma renúncia a altas ambições e levaria a um ensino de pouca qualidade, contrário à justiça democrática. Finalmente, podem-se apontar tensóes entre o movimento pelo qual, ao se massificarem e se tornarem um verdadeiro sistema (isto é, um conjunto de elementos interdependentes), as instituições escolares conheceram um processo de centralização, de uniformização e de padronização, e o movimento pelo qual, ao acolherem públicos mais numerosos e, portanto, mais heterogêneos, elas foram levadas, num dado momento, a deixar lugar para a diferenciação, a localização e a busca da autonomia de cada estabelecimento, na base de um projeto específico (Vincent, 1980). 
O terceiro nível no qual se pode analisar a noção de crise das instituições escolares é o dos fundamentos principiais. A escola, a "forma escolar" (definição de um local separado especialmente dedicado ao ensino; tempo escolar bem delimitado; conhecimentos transmitidos escapando à experiência trivial e à atualidade, visando à universalidade; organização em séries distintas segundo a idade; comportamento dos alunos regulado em função de uma série de normas), é essencialmente uma criação dos tempos modernos, da modernidade (séculos XVIIXVIII) na Europa (Vincent, 1980). Assim, a escola aparece como um modo de socialização historicamente situado, um momento novo no "processo de civilização"; inegavelmente, desde sua origem, ela mantém uma relação com o poder, uma vez que uma de suas funções primeiras é a incorporação da disciplina segundo todo um sistema de signos que servem a governar os alunos. Ora, esse poder não é apenas repressor. Nesse ponto, a análise de Foucault, como sempre muito útil e sutil, mostranos como, a partir do século XVII, o projeto da organização disciplinar, em particular na escola, visa a reprimir e acarretar docilidade, mas também como ele produz individualidade: trata de criar "mecanismos de poder que, ao invés de vir subtraindo, se integrem do interior à eficiência produtiva dos aparelhos" ${ }^{8}$ Essa análise singular, como outras também, mostra-nos que um dos efeitos da instituição escolar moderna é o de contribuir à promoção de um certo individualismo.

Muito rapidamente, a organização escolar entrou em ressonância com o ideal da democracia liberal (século XVIII). "Grandes narrativas" ou "metanarrativas", isto é, mitologias, acompanharam esse advento: crença, oriunda das Luzes, na idéia de uma emancipação do povo pela instrução, a Razão Científica - considerada o motor de todo progresso foi colocada no cerne do projeto escolar e dirigia-se a sujeitos racionais abstratos e, como tais, considerados intrinsecamente iguais. Ora, o que se constata hoje em dia é o esgotamento da capacidade dessas grandes narrativas a convencer, a ponto que "a nostalgia da narrativa perdida foi ela mesma perdida pela maioria das pessoas" (Lyotard, 1993). O que predomina é o lugar tomado pela dispersão, a fragmentação, o reino do aqui e do agora, o relativismo generalizado; estamos confrontados com uma dificuldade, senão uma impossibilidade, para encontrar o sentido (crise do sentido). Em suma, entramos na era pós-moderna, o que não podia deixar de abalar a escola: contestação dos saberes escolares pelos saberes "quentes", idéia de que todas as experiências se valem, denúncia 
Ainda é possível falar de escola “à francesa”? Algumas reflexões sobre as políticas...

do imperialismo do verdadeiro, contestação da autoridade professoral ou do adulto em geral, indivíduo caracterizado por suas clivagens ou dissociações internas (por exemplo, o aluno dividido entre a dimensão do estrategista calculador e a da pessoa autêntica) etc. Portanto, nesse nível de maior profundidade, a crise, aplicada à escola sem ser própria apenas da escola, é o hiato que surge entre essa escola, instituição específica da modernidade, e os "não-valores" da pós-modernidade. Caso se devessem adotar os princípios da pós-modernidade, como fazem certos pensadores, felizmente minoritários, mal vemos que futuro restaria para a instituição escolar tal como nos foi legado pela época moderna.

Este terceiro nível enfocou tendências que trabalham a realidade da sociedade e da escola contemporânea em geral; examinemos agora como uma de suas organizaçôes particulares, a francesa, administrou seus elementos de crise, pelo menos os da que chamamos de estrutural, e eventualmente encontrou equilíbrios internos.

\section{"Soluções" e equilíbrios temporários?}

Não entraremos aqui no detalhe factual (événementiel) das políticas educacionais: evocaremos apenas algumas de suas grandes características significativas para interrogá-las do ponto de vista das rupturas de equilíbrio que surgiram ou ameaçam surgir. Em referência ao horizonte francês, três aspectos retêm nossa atenção como expressões de problemas críticos: a "carta escolar" (carte scolaire), a relação unificação-diferenciação do sistema e a articulação entre igualdade de chances, meritocracia e individualismo.

Supostamente, a noção de "carta escolar" encarna o princípio republicano de igualdade de cada um com cada um no âmbito de uma oferta de educação pública eqüitativa no conjunto do território nacional, particularmente em matéria de escolarização secundária. Ela tem um lado dirigista no sentido em que levou ao recorte dos departamen$\operatorname{tos}^{9}$ em setores e distritos, os quais correspondem à área de recrutamento de um ou vários estabelecimentos públicos, nos quais são automaticamente matriculados os alunos que moram nas proximidades. Para poder ser justo, esse recorte havia de supor que os estabelecimentos secundários (colégios e liceus) existem em número suficiente e são mais ou menos eqüitativamente distribuídos; de fato, a massificação do secundário ou democratização quantitativa (aumento do número de alu- 
nos que podem seguir um currículo secundário sem distinção de classes sociais), resultado combinado de uma política voluntarista de formação e de uma demanda social crescente, desde o fim da Segunda Guerra Mundial, traduziu-se por uma política de construções escolares muito eficientes (anos de 1960). Confrontada, a partir dos anos de 1980, com os já mencionados comportamentos cada vez mais consumistas de certas famílias, essa política de carta escolar, que exprime, por assim dizer, o "planejamento à francesa" ${ }^{10}$ em nível da educação, teve de se afrouxar e oferecer derrogaçôes, em nome de uma maior liberdade e de uma melhoria do serviço público. De deslizes em deslizes, todos autorizados pelo Estado, surgiu o risco de que uma total desregulamentação se instaurasse e de que, na luta entre o "princípio patriótico" e o "princípio comercial" (como a descrevia um republicano do século XIX), este último levasse a melhor. Logo, depois de ter acompanhado e favorecido os afrouxamentos, o Estado, confrontado com as derivas ocasionadas notadamente nas grandes cidades e particularmente em Paris, decidiu "ressectorizar", isto é, voltar a uma aplicação mais estrita das regras, embora deixando ainda algumas margens de manobra controladas de modo que se chegasse a uma concorrência regulada, dominada por regras transparentes (fim dos anos de 1990). Obviamente, esse dispositivo não impede que as famílias mais abastadas em capital cultural e social desenvolvam estratégias ganhadoras para contornar as regras (fenômeno que se acentuou no início dos anos 2000). Está claro que a política educativa não pode ser declarada responsável pelas formas de segregação urbana vinculadas às políticas sociais e de habitação, mas, ao menos em termos de princípios, o Estado conseguiu estabelecer um equilíbrio relativo entre rigor republicano, com suas limitações, e inclinação consumista das famílias, com sua reivindicação de liberdade. A margem é estreita entre serviço público rígido, inacessível aos pedidos precisos do público, e simples serviço do público, que ignora o interesse geral.

Em termos de evolução dos princípios organizacionais, se fizermos um balanço de 50 anos de política educativa na França, o fato principal que emerge é o da unificação das estruturas escolares, que levou a um verdadeiro sistema educativo caracterizado pela interdependência de suas componentes. Ora, em todas as reformas, quer de direita ou de esquerda, é a democratização que vem justificar essa unificação. De fato, passou-se de uma organização em ordens independentes compartimentadas 
Ainda é possível falar de escola “à francesa”? Algumas reflexões sobre as políticas...

(o primário, reservado ao povo, separado do secundário, ele mesmo relacionado ao superior, mas contemplando apenas um pequeno número de alunos do Ensino Fundamental e Superior oriundos da burguesia) a uma organização por graus sucessivos, na qual todas as crianças são chamadas a cursar pelo menos até a $8^{a}$ série. Devida tanto ao voluntarismo político dos governos quanto às exigências econômicas (em particular a competição internacional e a requalificação dos empregos) e a uma demanda social das famílias favoráveis à elevação do nível de formação de seus filhos, a democratização quantitativa da educação foi espetacular: passou-se, assim, de 309.700 estudantes em 1960 (para uma população de aproximadamente 45 milhões de habitantes) a 1.220 .000 em 1981 e 2.200 .000 em 1995 (aproximadamente $60 \mathrm{mi}$ lhôes de habitantes); a esperança média de escolarização de uma criança francesa de 5 anos era de 16,5 anos em 1999 (OCDE-CERI, 2001). Resta a questão da democratização qualitativa, isto é, da relação mais ou menos proporcional que existe entre a estruturação da população em categorias socioprofissionais e seu reflexo na instituição escolar, segundo o prestígio mais ou menos elevado de tal ou tal filière, de tal ou tal diploma. Se considerarmos esse aspecto qualitativo, temos de constatar que, globalmente, a democratização não progrediu e que as filières mais prestigiosas continuam freqüentadas pelas crianças oriundas das classes mais favorecidas, o que levou um observador a evocar o paradoxo de uma democratização "segregativa" (Merle, 2002). Apesar disso, no mesmo período, um número considerável de filhos de operários e de empregados-funcionários ascendeu a níveis escolares que eram totalmente proibidos a seus pais.

Sem dúvida alguma, nesse âmbito de manutenção da unificação nacional, o outro fato que caracteriza a evolução mais recente do sistema educativo é a descentralização e, mais amplamente, a territorialização ou localização parcial das políticas escolares. Esse movimento também encontra sua legitimação na vontade de introduzir mais justiça nas instituições escolares na forma de uma justiça distributiva, uma vez que o modelo baseado apenas na igualdade de direito revelou seus limites, e até mesmo suas mistificações. Assim, umas regulações locais e a introdução de formas de discriminação positiva (tratamento diferenciado de situaçôes e pessoas elas mesmas diferentes ${ }^{11}$ serviram para favorecer a marcha rumo a esse aumento de igualdade visado pela política de democratização. Haveria uma contradição no fato de esses dois 
processos com orientações a priori opostas, o da unificação (que, durante muito tempo, pareceu significar - ao menos num plano formal - a padronização dos ensinamentos e dos estabelecimentos) e o da descentralização-territorialização (que privilegia as diferenciações e os caracteres específicos dos escalóes locais), justificarem-se em referência ao mesmo projeto de democratização? Será que assistimos a uma revolução silenciosa que, por um deslocamento progressivo de uma polaridade dominante à outra, modificou radicalmente as bases do sistema? Parece que, resultado ao mesmo tempo de vontades expressas e de fenômenos menos diretamente controlados, um equilíbrio frágil, mas por enquanto real, foi encontrado entre manutenção da referência ao princípio de unificação-padronização (pilotagem central, retribuição, recrutamento e formação pelo Estado dos funcionários, programas e exames com caráter nacional) e apelo ao princípio da diferenciação-territorialização das ações educativas (transferência de responsabilidades às coletividades territoriais, maior autonomia concedida aos estabelecimentos, afrouxamento da carta escolar, definição de zonas difíceis que recebem recursos privilegiados ${ }^{12}$ ). Esse equilíbrio relativo, em benefício, afinal de contas, do princípio hegemônico de unificação, fez com que o juiz constitucional considerasse que não houve "ruptura caracterizada" 13 da tradição republicana à francesa.

Outra maneira de apreender a questão dos equilíbrios internos, mantidos ou rompidos, consiste em examinar como, dentro da instituição escolar após a Segunda Guerra Mundial, combinaram-se três orientações fundadoras: a da chamada igualdade de chances, a da meritocracia e a da preocupação individualista. Embora a primeira se situe no princípio mesmo da escola republicana, ao menos no plano declarativo, ela teve de esperar quase um século para se ver posta em adequação com a organização efetiva do sistema (abertura formal do conjunto dos currículos a todos). A segunda significa que, aqui também em princípio, apenas o mérito do aluno, independentemente de toda outra consideração, é levado em conta no processo de seleção nas diferentes etapas da escolaridade. Finalmente, a terceira orientação deve-se ao fato de que, sem esperar a proclamação do "aluno no centro do sistema” em 1989, ${ }^{14}$ a escola preocupou-se com a pessoa do aluno (não somente em nível pré-elementar) e com seu desabrochar individual. Segundo um analista tão avisado quanto Marcel Gauchet, essas três orientações, embora contenham tendências potencialmente antitéticas entre si, conseguiram coexistir juntas: 
Ainda é possível falar de escola “à francesa”? Algumas reflexões sobre as políticas...

A escola do Estado-Providência opera a síntese (...) da meritocracia republicana, da igualdade social de massa e da preocupação individualista. (...) ela tenciona garantir ao mesmo tempo a igualdade de chances, (...) a abertura a todos da melhor educação possível, sem deixar de ministrar, nesse âmbito, uma educação individual e livre. E, ó milagre, ela conseguiu numa ampla medida. (Gauchet, apud Blais, Gauchet \& Ottavi, 2002, p. 33)

Embora, para este autor, "hoje em dia, o equilíbrio está rompido (...) a tendência ao individualismo levou a melhor sobre todo o resto", por nosso lado, consideramos que, apesar do aumento inegável da tendência ao individualismo na sociedade e na escola, a ruptura desse equilíbrio não está comprovada e que, além das dificuldades enfrentadas pelo sistema (entre as quais a da democratização qualitativa não é a menor, já que questiona fortemente a noção de igualdade das chances iniciais), as três orientações continuam funcionando juntas. A nosso ver, a maioria dos docentes não aderiu à idéia de fazer triunfar o individualismo em detrimento de outros valores, como a ascese do saber, principalmente no ensino secundário. Portanto, um equilíbrio precário ainda se mantém entre as três orientações.

\section{Pistas para o futuro}

Em muitos pontos, como acabamos de vê-lo, a escola à francesa situa-se a meio caminho entre práticas e valores herdados de sua tradição e adaptações às exigências conjunturais contemporâneas. Essa situação provoca um equilíbrio temporário, frágil, cujos limites e riscos de ruptura são fáceis de perceber (para certos observadores, essa ruptura já aconteceu). Seja como for, esse equilíbrio remete ao passado, e a manutenção de uma escola conforme a nossos valores supóe olhar para o futuro colocando condições de viabilidade que respeitem esses valores. Aqui, é claro, as convicçôes prevalecem sobre a análise, embora se esforcem por permanecer coerentes com esta; para ter chances de serem eficientes, elas precisam integrar-se a intervenções de natureza fundamentalmente política.

Ter consciência das manifestações pós-modernas, que evocamos anteriormente, não significa automaticamente aderir a uma filosofia pósmoderna. "O antigo princípio de que a aquisição do saber é indissociável da formação (Bildung) do espírito e mesmo da pessoa está ficando cada vez mais obsoleto." Caso essa predição do filósofo J.-F. Lyotard fosse 
transformada em programa, ela significaria o fim da instituição escolar. Será que uma nova grande narrativa unitária produtora de sentido para uma escola futura, uma escola ideal, poderá estorvar esse pessimismo pós-moderno e se substituir às antigas grandes narrações tornadas obsoletas? Fazendo às vezes de profetas, alguns pedagogos acreditam que sim. Por nosso lado, não acreditamos nisso e nos contentaremos em formular modestamente algumas pistas para um futuro próximo.

Como a educação e a instrução são bens em si, esses bens não são em nada "mercadorizáveis". Isso significa uma recusa categórica do neoliberalismo, que gostaria de se apoderar da escola e submetê-la a imperativos ditados pela esfera econômica e pelo lucro. De fato, a partir do momento em que apenas o lucro está na base da difusão dos bens escolares, fica claro que o valor intrínseco destes importa pouco e que o que predomina é a submissão a interesses mercantis imediatos. Há nisso uma fonte de oposição central aos ideais da democracia e da democratização que supõem que o maior número e até mesmo a totalidade dos cidadãos tenham acesso aos saberes e à melhor educação, de modo tendencialmente "desinteressado", ou ao menos segundo valores nobres, tais como a participação igualitária na vida democrática e na cultura, sem, entretanto, desconsiderar o realismo econômico que requer levar em conta a natureza dos empregos disponíveis.

Bens em si, educação e instrução contêm - na tradição republicana - uma orientação para a universalidade que não pode pô-los sob a dependência exclusiva de decisões locais, comunitárias, privadas, em ruptura com a referência à noção de bem público, e isso independentemente do modo de organização estrutural da escola. A coexistência entre o público e o privado (religioso), além de ser um fato (na França, $80 \%$ dos alunos estudam no público, 20\%, no privado), é aceitável contanto que tenham sido definidas e verificadas as condições em que o próprio privado contribui para o serviço público de educação, no âmbito de um contrato com o Estado (respeito dos programas, e dos grandes valores nacionais). Mais geralmente, o que torna aceitável o ensino privado pago - pois ele é obviamente guiado por um princípio de rentabilidade - é sua participação na difusão de conteúdos de ensino com orientação universal, e não particularista ou sectária.

Bens em si, educação e instrução devem ser desejáveis para a maioria dos jovens a quem se dirigem, o que coloca a questão da cultura escolar e dos conteúdos de ensino no centro da presente reflexão sobre a es- 
Ainda é possível falar de escola “à francesa”? Algumas reflexões sobre as políticas...

cola. Essa cultura não pode ser reduzida apenas à dimensão da Razão Abstrata: ela deve deixar lugar à imaginação, à criatividade, às diversas sensibilidades artísticas e corporais e, desse ponto de vista, integrar as contribuições da nova educação. Mesmo se nos ativermos apenas à cultura científica, que hoje em dia suplantou em prestígio as humanidades, a epistemologia contemporânea mostra-nos o quanto uma imaginação quase poética deve ser combinada ao rigor lógico, e como o raciocínio científico vai às vezes buscar seus modelos na poesia e na literatura. ${ }^{15}$ Com Michel Foucault ainda, que denunciava a monotonia de tantas e tantas situações escolares, iríamos até evocar uma "erótica" do saber e da verdade que a escola por vir deveria criar.

Obviamente, a escola por vir não poderá desconsiderar o sujeito, a pessoa. Durante muito tempo, por razões políticas e filosóficas, a escola republicana apenas quis reconhecer nos indivíduos que lhe eram confiados sujeitos racionais abstratos. Essa posição não é mais sustentável. Faz 30, 40 anos que, ao se democratizar e ao acolher crianças cada vez mais numerosas e de todas as origens no secundário, ela vem sendo confrontada com a necessidade de levar em conta os sujeitos singulares em todas as suas dimensóes. Existe um apelo ao "respeito" e à "autenticidade" de sua pessoa, no que toca aos alunos, que não pode ser ignorado. A dificuldade, para a escola, consiste em encontrar uma conciliação entre a construção do sujeito racional crítico (que supõe a submissão a certas regras) e a construção da pessoa autêntica (que remete ao exercício da liberdade). Mais uma vez, é útil escutar Foucault, que via na situação pedagógica, do ponto de vista do aluno, "o encontro do saber outro como o que altera sem alienar na aventura de tornarse Si Mesmo"; e ele fazia questão de colocar o problema em termos de "práticas de si e de liberdade". ${ }^{16}$

Finalmente, não podemos esquecer a necessidade de uma escola da diversidade e da mescla social. De fato, desde sua origem, a função da instituição escolar pública consiste em reunir as novas geraçôes em torno da transmissão de saberes e valores com alcance tendencialmente universal; portanto, a escola não pode se acomodar numa deriva, da qual ela não é a única responsável, que leva à exclusão recíproca de populações escolares em função de seu pertencimento social, cultural, étnico. De uma certa forma, as dificuldades da escola provêm de seus próprios sucessos, da exigência, vinda de todas as partes, de levar os jovens à melhor qualificação possível; é o que se poderia chamar de pedagogização do 
conjunto da sociedade, ou seja, a idéia segundo a qual o mais alto nível de formação constitui a melhor garantia de êxito na inserção na sociedade. Como essa idéia (amplamente verificada) é compartilhada por todas as categorias sociais, é inaceitável que as mais desfavorecidas entre elas sejam confinadas em estabelecimentos de menor qualidade pelos efeitos da segregação urbana e da concentração das mesmas populações nos mesmos lugares. Aqui, dentro da ação política, uma vigilância deve ser exercida, corretivos devem ser aplicados, dos quais uma escola futura deveria tirar benefícios.

Já ficou claro que nossa posição não é: é preciso que tudo fique como está, e que as "exceções nacionais" não sejam reativas às solicitações externas, em particular supra-estatais. A nosso ver, o que está em jogo é continuar a preservar, pela escola, o acesso das jovens geraçóes ao universal, não esse falso universal relacionado a um sentimento de superioridade nacional (em nome do qual o colonialismo foi tantas vezes justificado), nem esse outro falso universal da uniformidade mundial (submetido a valores de inspiração principalmente econômica), mas um universal se possível melhor. Ora, este não se adquirirá pela dissolução das "exceções nacionais", mas - a partir delas - pela crítica de suas derivas e pelo aprofundamento do que elas trazem de melhor, assim como pela sua convergência refletida e dominada com outras. Lembrando Hegel, reafirmaremos que o universal apenas existe na particularidade, contanto que esta não degenere em particularismo.

Recebido em fevereiro de 2006 e aprovado em maio de 2006.

\section{Notas}

1. Definida sumariamente pelos traços seguintes: globalização dos mercados e da produção, transformação do espaço-tempo por meio da inovação tecnológica, homogeneização cultural.

2. A expressão é retomada de Althusser (in: Althusser \& Balibar, 1969, p. 28 e ss).

3. A mesma crítica pode se aplicar, apesar de certas qualidades, às obras mais recentes de Eliard (1984) e Careil (2002).

4. Organizações espontâneas e temporárias, criadas fora dos sindicatos, em torno de uma reivindicação bem precisa.

5. Na França, uma "carta escolar" determina, em princípio, a admissão de uma criança em tal ou tal estabelecimento escolar em função do lugar de residência de sua família; cf. infra.

6. É essa ação consciente que os quebequenses chamam apropriadamente de "o processo político de decisão", em La gouverne de l'éducation, logique marchande ou processus politique? 
Ainda é possível falar de escola “à francesa”? Algumas reflexões sobre as políticas...

Rapport annuel sur l'Etat et les besoins de l'éducation, Conseil Supérieur de l'Education, Québec, 2001.

7. Vários países da Europa do Sul têm a mesma organização.

8. Fundados sobre o poder e a disciplina, escola, prisão, hospital e fábrica contribuem para constituir o indivíduo como sujeito descritível; cf. Foucault (1975, p. 255).

9. Unidades administrativas de recorte territorial francês.

10. A concepção francesa do plano pretendia combinar economia liberal e previsão "antiacaso".

11. Onde, anteriormente, o sistema francês caracterizava-se, segundo P. Bourdieu e J.-C. Passeron, por sua "indiferença às diferenças".

12. "Dar mais a quem tem menos" é o slogan que presidiu à criação das Zonas de Educação Prioritária (ZEP) (1981).

13. Cf. Conselho de Estado, Relatório Público, 1996.

14. Relatório anexado à lei de orientação sobre o sistema educativo (dita Lei Jospin).

15. Cf., por exemplo, Lévy-Leblond (1996).

16. Citado por Audureau (2003, p.17-27); grifo nosso.

\section{Referências bibliográficas}

ARCHER, M. Social origins of educational systems. London: Sage, 1979. ALTHUSSER, L.; BALIBAR, E. Lire le capital. Paris: Maspero, 1969. v. 1 , p. $28-$

AUDUREAU, J.-P. Assujettissement et subjectivation: réflexions sur l'usage de Foucault en éducation. Revue Française de Pédagogie, Paris, n. 143, p. 17-27, 2003.

BALLION, R. Les consommateurs d'école. Paris: Stock, 1982.

BAUDELOT, C.; ESTABLET, R. L'école capitaliste en France. Paris: Maspero, 1971.

BEAUD, S. $80 \%$ au bac... et après?: les enfants de la démocratie scolaire. Paris: La Découverte, 2002.

BLAIS, M.-C.; GAUCHET, M.; OTTAVI, D. Pour une philosophie politique de l'éducation: six questions d'aujourd'hui. Paris: Bayard, 2002 BOUDON, R. L’inégalité des chances. Paris: A. Colin, 1973.

BOURDIEU P.; PASSERON, J.-C. La reproduction. Paris: Minuit, 1970. 
CAREIL, Y. De l'école publique à l'école libérale. Rennes: PUR, 1998.

CAREIL, Y. Ecole libérale, école inégale. Paris: Syllepses, 2002.

CHARLOT, B. (Coord.). L'école et le territoire. Paris: A. Colin, 1994.

CHERKAOUI M. Les changements du système éducatif en France 19501980. Paris: PUF, 1982.

DEROUET, J.-C. Ecole et justice. Paris: Métailié, 1992.

DUBET, F. Les lycéens. Paris: Seuil, 1991.

DUBET, F.; DURU-BELLAT, M. L'hypocrisie scolaire: pour un collège enfin démocratique. Paris: Seuil, 2000.

DURKHEIM, E. L'évolution pédagogique en France. 2.ed. Paris: PUF, 1969.

DURU-BELLAT, M.; VAN ZANTEN, A. Sociologie de l'école. 2. ed. Paris: A. Colin, 1999.

DUTERCQ, Y. Politiques éducatives et évaluation. Paris: PUF, 2000.

EL HACHEM T. A quoi sert le Plan? Paris: Economica, 1992.

ELIARD, M. L'école en miettes? Paris: PIE, 1984.

FOUCAULT, M. Surveiller et punir. Paris: Gallimard, 1975.

FOUCAULT, M. Dits et écrits. Paris: Gallimard, 2001. v.1.

ISAMBERT-JAMATI, V. Brève histoire d'une notion incertaine: la démocratisation. Cahiers Pédagogiques, Lyon, n. 107, oct. 1972.

KERLAN, A. Philosophie pour l'éducation. Paris: ESF, 2003.

LANGOUËT, G.; LÉGER, A. Le choix des familles: école publique ou école privée? Paris: Fabert, 1997.

LELIÈVRE, C. L'école "à la française" en danger? Paris: Nathan, 1996. LÉVY-LEBLOND, J.-M. La pierre de touche. Paris: Gallimard, 1996. LYOTARD, J.-F. La condition postmoderne. Paris: PUF, 1993.

MERLE, P. La démocratisation de l'enseignement. Paris: La Découverte, 2002. 
Ainda é possível falar de escola “à francesa”? Algumas reflexões sobre as políticas...

NÓVOA, A. Histoire et comparaison: essais sur l'éducation. Lisboa: Educa, 1998.

OCDE-CERI. Regards sur l'éducation. Paris, 2001.

PROST, A. Histoire de l'enseignement en France, 1800-1967. Paris: A. Colin, 1968.

QUÉBEC. CONSEIL SUPÉRIEUR DE L'EDUCATION. La gouverne de l'éducation, logique marchande ou processus politique? ; rapport annuel sur l'Etat et les besoins de l'éducation. Québec: Conseil Supérieur de l'Education, 2001.

ROBERT, A. Système éducatif et réformes, 1944-1993. Paris: Nathan, 1993.

ROBERT, A. Le syndicalisme des enseignants. Paris: La Documentation Française; CNDP, 1995.

ROBERTSON, R. Globalization: social theory and global culture. London: Sage, 1992.

VAN ZANTEN, A. L'école de la périphérie. Paris: PUf, 2001.

VAN ZANTEN, A. Les politiques d'éducation. Paris: PUF, 2004.

VAN ZANTEN, A. L'action éducative à l'échelon municipal: rapport aux valeurs, orientations et outils. In: CARDI, F.; ChAmBOn, A. Les métamorphoses de la formation. Paris: L'Harmattan, 1997. p. 165-185.

VASCONCELLOS, M. Le système éducatif. Paris: La Découverte, 2004.

VINCENT, G. L'école primaire française. Lyon: PUL, 1980. 